\title{
Nordic walking training and nutritional supplementation in pre-frail older Indians: an open-labelled experimental pre-test and post-test pilot study to develop intervention model
}

Prasun Chatterjee ${ }^{1}$, Prakash Kumar ${ }^{1}$, Ramesh Kandel ${ }^{2}$, Ruchika Madan ${ }^{1}$, Meenakshi Tyagi ${ }^{1}$, Deepa Anil Kumar ${ }^{3}$, Maroof Ahmad Khan ${ }^{4}$, Gaurav Desai ${ }^{1}$, Preeti Chaudhary', Shyama Gupta ${ }^{5}$, Kanika Grover ${ }^{6}$ and Aparajit Ballav Dey ${ }^{1 *}$

\begin{abstract}
Background: Identifying and treating people in a pre-frail state may be an effective way to prevent or delay frailty and preserve their functional capacity. This study aimed to assess the efficacy of, and compliance with, a 12 week individualized nutritional supplementation (INS) and Nordic walking (NW) program in pre-frail older Indians. The primary measure is physical performance, as indicated by Fried's Frailty scale. Other measures include: cognition, as indicated by the Hindi Mental Status Examination; mood, by the Geriatric Depression Scale; and nutritional status, by the Mini Nutritional Assessment.
\end{abstract}

Methods: This is an open-labeled experimental pre-test and post-test study, which took place from October 2012 to December 2014. The study was approved by Institute Ethics committee (IEC/NP-350/2012/RP-26/2012) at the All India Institute of Medical Sciences (AlIMS), New Delhi. Participants were sixty-six pre-frail elderly, who were randomly allocated into three subgroups, namely: A (NW only), B (INS only), and C (NW and INS). One-way ANOVA was used to statistically assess differences in baseline characteristics for quantitative variables, with the Chi-Square/Fischer exact test utilized for qualitative variables. Paired t-tests were used to assess pre and post intervention difference within the group for quantitative variables, with McNemar's Chi-Square test used for qualitative variables. Kruskal Wallis test was used to assess significant intervention effects among the groups. A $p$-value $<0.05$ was considered as statistically significant.

Results: There was significant effect of intervention in gait speed in group $\mathrm{A}(p=0.001)$ and $C(p=0.002)$, but not in group $B(p=0.926)$. While there was no significant change in grip strength in Group $A(p=0.488)$ and $B(p=0.852)$, a statistically significant increase was observed in group $C(p=0.013)$. Mood significantly improved in group $B(p=0.025)$ and $C(p=0.021)$. No significant difference was noted in cognitive status across groups. Following the interventions, a total of $18.18 \%$ of pre-frail participants were classified as non-frail.

Conclusions: Combining NW and INS provides a simple, pragmatic intervention with efficacy in the management of functionally vulnerable older adults, and allows their maintained independence. Future studies should replicate this readily applicable intervention in a larger cohort with a longer follow-up period.

(Continued on next page)

\footnotetext{
* Correspondence: abdey@hotmail.com

${ }^{1}$ Department of Geriatric Medicine, All India Institute of Medical Sciences,

New Delhi, India

Full list of author information is available at the end of the article
}

(c) The Author(s). 2018 Open Access This article is distributed under the terms of the Creative Commons Attribution 4.0 International License (http://creativecommons.org/licenses/by/4.0/), which permits unrestricted use, distribution, and reproduction in any medium, provided you give appropriate credit to the original author(s) and the source, provide a link to the Creative Commons license, and indicate if changes were made. The Creative Commons Public Domain Dedication waiver (http://creativecommons.org/publicdomain/zero/1.0/) applies to the data made available in this article, unless otherwise stated. 
(Continued from previous page)

Trial registration: Clinical Trial Registry-India CTRI/2016/05/006937 [Registered on: 16/05/2016]; Trial was Registered Retrospectively.

Keywords: Frailty, Adapted indoor Nordic walk, Individualized nutritional supplementation

\section{Background}

Frailty syndrome is arguably the greatest challenge faced by an aging population. It also has obvious significance for clinicians, scientists and policy planners [1]. Frailty syndrome is a state of increased vulnerability due to poor resolution of homeostasis after a stressor event, thereby increasing the risk of adverse outcomes including falls, delirium and disability [2]. The paradigm of precision medicine may be readily applied to the concept of frailty, allowing its better management within main stream modern medicine [3]. The prevalence of frailty is variable across studies, due to differences in defining criteria and study samples. In community dwelling western population over the age of 65 years, a systematic review indicates an overall frailty prevalence of $10.7 \%$, which increases with age, being evident in $15.7 \%$ in 80 to 84 year olds and $26 \%$ in those over 85 years of age [3].

'Fitness' and 'frailty' may be seen as forming the poles of a continuum [4], with the former indicating complete independence, and the latter indicating complete dependence. Age-associated progression along this continuum often results in stages from healthy, to a semi-robust, subclinical frailty, to a pre-frail and eventual frail state [5]. Frail populations have a substantially increased risk of falls, disability, and the need of institutional care as well as of mortality [6]. Systematic reviews indicate that the pre-frail state, an intermediate stage between non-frail and frail, to have a $41.6 \%$ prevalence in community samples, compared to the $10.7 \%$ prevalence of a frail state [7]. One study of an Indian tertiary care hospital shows a $21 \%$ frailty prevalence and a $20 \%$ pre-frailty prevalence, using Fried's phenotypic criteria [8].

Pre-frail individuals have more than twice the risk of becoming frail compared to non-frail people [9]. Identifying and treating people in the pre-frail state is an opportunity to prevent or effectively delay frailty. Further, evidence suggests that older adults in a pre-frail, compared to a frail, state respond better to more intensive interventions [10].

Frailty has a multi-faceted pathogenesis and pathophysiology, with sarcopenia proposed to play an important role $[8,11]$. Sarcopenia is a syndrome that is characterized by the progressive and generalized loss of skeletal muscle mass and strength, thereby increasing the risk of many adverse outcomes, including physical disability and poor quality of life, as well as and mortality [12]. Consequently, interventions focused on improving muscle strength should have utility. However, improving muscle strength can be challenging, given its dependence on multiple factors, such as nutritional status [13], and the functional capacity of the individual [14]. Numerous multi-factorial interventions consisting of nutritional supplementation and various forms of exercise have been studied in the frail elderly, with variable results [15-17]. Unfortunately, the compliance to regular exercise in frail older adults is low, due to intrinsic weakness, lack of inertia and the perceived risks of exercise [18]. Resistance training and/or diet seem the only effective interventions to treat or prevent sarcopenia in frail or pre-frail individuals [13].

Walking is a rhythmic, dynamic, and aerobic activity with numerous benefits for the musculoskeletal system and almost no negative effects [19]. Nordic walking (NW) is a form of walking that uses muscles of the upper and lower body in a continuous and reciprocal movement [20] (Fig. 1). Due to the higher muscle mass involved, NW produces a higher cardio-respiratory workload, whilst improving endurance and flexibility as well as benefitting body balance functioning [21]. It is a whole-body aerobic or alternating aerobic/anaerobic discipline, rarely associated with physical injury and easily practiced by people of all ages, including older adults [15, 22-24]. A systematic review and meta-analysis by Bullo et al. summarizes the effectiveness of NW interventions on the physical fitness and quality of life in the elderly [25].

Inadequate dietary intake, especially of proteins and amino acids contributes to the development of sarcopenia and frailty [26-29], with a noticeable improvement in muscle strength occuring after protein and micro-nutrients supplementation [26]. Nutritional supplementation (protein and amino acid) in combination with physical training could further improve the functional status in frail populations. However, such work has focused on the combination of nutritional supplementation plus exercise for all study participants. It is important to clarify the relative contributions of exercise and diet. We hypothesized that, without pain and discomfort, an older person performing NW with individualized nutritional supplementation for 12 weeks would show a $20 \%$ greater improvement, versus either NW or INS alone. The current investigation is a pilot initiative study evaluating the efficacy of NW in functionally vulnerable older Indians, with or without INS, as well as in comparison to INS alone.

\section{Methods}

This is an open-labeled experimental pre-post study from October 2012 to December 2014. The study was 

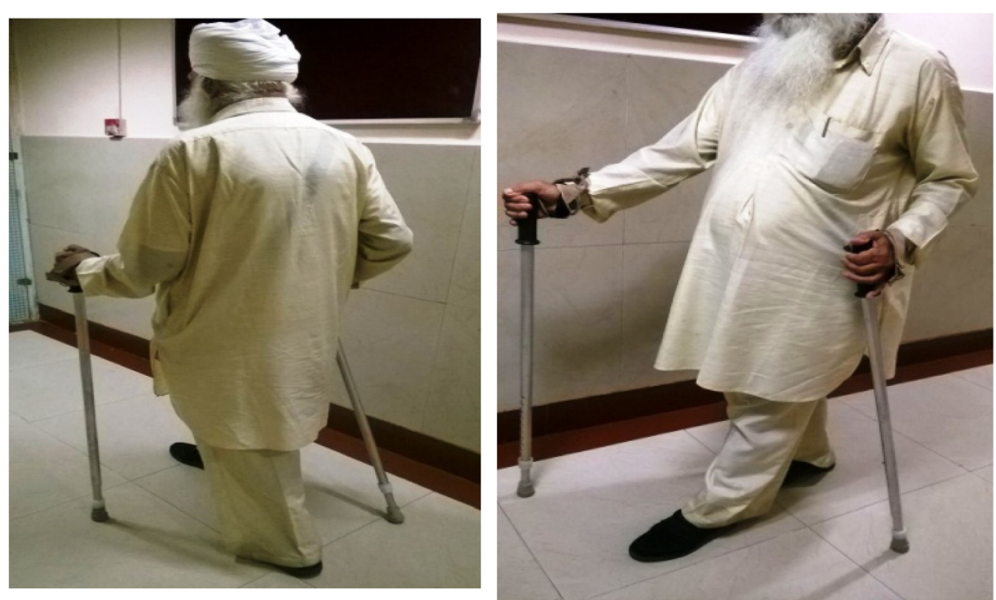

Fig. 1 Adapted indoor Nordic Walk training

conducted with the approval of the Institute Ethics committee of All India Institute of Medical Sciences (AIIMS), New Delhi (Ref. No: IEC/NP-350/2012/RP-26/2012).

Participants: Individuals aged 60 years and above were recruited from the out-patient department of Geriatrics Medicine, AIIMS. Study inclusion criteria were: Pre-frail, as assessed by a Fried's phenotypic scale [30] score of 1 or 2. Exlusion criteria: Any form of resistive training exercise or nutritional supplementation in the previous 6 months; having an acute illness, severe obstructive airway disease (Forced ExpiratoryVolume $<30 \%$ ); severe systolic dysfunction (Ejection Fraction $<30 \%$ by Echocardiogram); severe depression (Geriatric Depression Scale $>11$ ); severe, painful lower limb muscle condition; and severe cognitive impairment (Mini-Cog $=0$ ).

As per the out-patient department posting schedule of the first author (PC) and the principal investigator (ABD), three patients were randomly selected after obtaining consent to carry out frailty assessment. This was done three times a week for 18 months, giving a total of 648 patients. Of these 648 patients, 129 were found to be pre-frail as per Fried's criteria. However, 63 patients declined to participate in the study, due to a variety of reasons, including transport, mobility issues and the lack of care giver support. Consequently, the 66 patients who gave informed written consent were recruited into the study.

A standard randomization procedure for intervention allocation was generated using the n-query 2.0 software and allocation of the participants in three groups was done by sequentially numbered opaque sealed envelope. Sixty-six participants were therefore randomly allocated into three groups of twenty-two: Group A: NW; Group B: INS; and Group C: NW + INS (Fig. 2).

Demographic details including age, gender, education and income were obtained. A detailed assessment on nutritional status and physical performance was carried out by a qualified nutritionist (Masters degree in Food and Nutrition with two-years research experience in Geriatric Medicine) and an occupational therapist (Bachelors degree in Occupational Therapy with two years of clinical research experience in geriatric medicine), which provided baseline scores on these parameters.

Nutritional assessment was carried out by anthropometric measures, including weight, height, body mass index (BMI), and mid upper arm circumference (MUAC). A MUAC $<23.5 \mathrm{~cm}$ in males and $<22 \mathrm{~cm}$ in females was indicative of malnutrition. The nutritional status of the participants was assessed by Mini Nutritional Assessment $\left(\mathrm{MNA}^{\circ}\right.$, Nestle Nutrition Institute) [31], an 18-point questionnaire with a maximum score of 24. Participants scoring < 17, 17-23.5 and 24-30 were labelled as 'Malnourished', 'At risk of malnutrition' and with 'Normal nutritional status' respectively.

To determine the concentration of serum albumin $5 \mathrm{ml}$ blood was drawn from each study participant at baseline and after intervention. Serum was separated and albumin concentration was determined using standard protocols. Various functional assessments were performed. The assessment of the physical domain utilized the Modified Physical Performance Test (MPPT) and Berg Balance Scale (BBS). MPPT consists of nine components each with a minimum score of zero and maximum of 4 (total:36) [32]. Participants scoring between 0 and $16,17-24,25-31$ and $32-36$ are classified as severe, moderate, mild and non-frail, respectively. The BBS measure of balance consists of a 14-item scale designed to measure balance of the older adult in a clinical setting out of a total score of 56 . Based on the scoring between 0 and 20, 21-40 and 41-56, participants were categorized into 'low risk', 'medium risk' and 'high risk' group respectively [33]. The assessment of daily living 


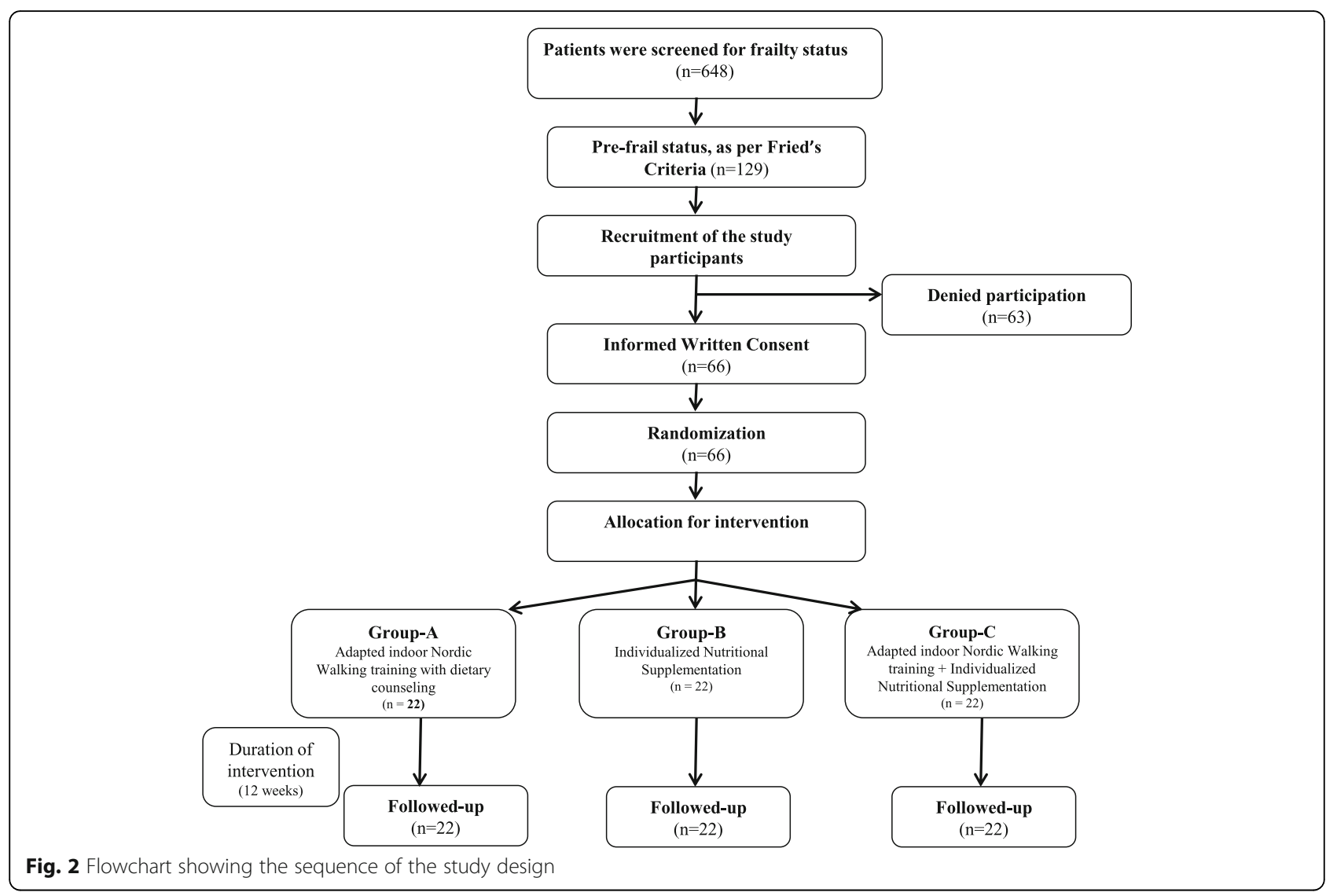

functioning utilized the 'Barthel activity of daily living (BADL)' and 'Lawton and Brody instrumental activity of daily living (IADL).' The BADL is an ordinal scale with 10 components, scored either 0 or 1 , giving a total scale range of $0-20$ [34]. The IADL consists of eight components, scored either 0 or 1 , giving a total scale range of $0-8$ [35]. Mood was assessed by 15 -item short form of the geriatric depression scale (GDS), with a score over 5 denoting depression [36]. The cognitive domain was assessed by the 'Hindi Mental Status Examination (HMSE)' scale. The HMSE is a 23-item questionnaire with a maximum score of 30 . Patients scoring less than 24 are regarded as cognitively impaired [37].

Frailty Assessment: Frailty was assessed by Fried's phenotypical criteria [30], whereby one point is scored for each criterion met to specification. The components were: a) slow walking speed -walking $0.6 \mathrm{~m} / \mathrm{sec}$ with or without a walking aid. b) Weakness (grip strength) was measured using hand dynamometer (in $\mathrm{kg}$ ), taking the best of three attempts, with a grip strength of less than $6 \mathrm{~kg}$ in females and less than $15 \mathrm{~kg}$ in males as positive indicant of frailty. These cut-offs are also the 25th percentile of age matched control, which were taken as cut off value in previous published data from AIIMS [38]. c)
An unintentional loss of weight greater than $5 \%$ of body weight or $10 \mathrm{lb}$. in the last one year was taken as positive indicant of frailty. d) Self Reported Exhaustion in the previous week, as indicated by response to being asked how often they felt that "everything they did was an effort" and "whether they could get going?". Answer indicating this to be for3-4 days in the past week were taken as positive indicants of frailty. e) Low Physical Activity (over the past three months), with positive indicants of frailty being "not performing minimum weight-bearing physical activity" or "spending more than 6 hours per day sitting or lying other than sleep time." Individuals with 3 or more of these characteristics were considered as frail, with those having 1 or 2 of these scale characteristics regarded as pre-frail.

\section{Adapted indoor Nordic walking training}

The participants were trained for 12 weeks (36 training sessions each of 60 min duration), with a frequency of three times a week. Training sessions were individualized and provided by a qualified physiotherapist having Masters in Physiotherapy, with specialization in Orthopaedics, and using the NW technique according to the guidelines of the International Nordic Walking Federation (INWA) 
[39]. Each training session began with a short warm-up (5-10 min) which consisted of flexibility exercise for upper and lower extremities and spine. Training ended with stretching and breathing exercises (3-5 min). The pole length was adopted according to the participant's physique, permitting a smooth arm motion and based on the INWA formula $(0.7 \mathrm{X}$ height $\mathrm{cm})$. NW took place in a departmental corridor. Two walking poles were used to push against the ground with each stride, actively engaging the trunk and upper limbs during walking and maintaining natural gait, whilst the hands performed an open-close cycle in an alternating manner [15] (Fig. 1). Therapist walked side by side with the participant, providing encouragement throughout the walking sessions. During this training period, participants did not engage in any other physiotherapy and occupational therapy programs. Assessment of post-intervention dependent variables was done within 1 week of the final NW session.

Nutritional Intervention: Considering the high prevalence of malnutrition in India [40] the present study carried out assessment for both calorie and protein deficiency, with supplementation given as required. Calorie and protein requirement of each participant were assessed by a nutritionist. The participants from group A were counselled at baseline about their deficiency and were asked to improve their nutritional status by improving their diet. Participants belonging to group $\mathrm{B}$ and $C$ were supplemented with the deficit quantity of nutrients, as per individual need, for 12 weeks. Carbohydrates were supplemented at the rate of $\approx 50 \%$ of total daily calorie requirement and protein was supplemented at the rate of $1.2 \mathrm{~g} / \mathrm{kg}$ body weight. The objective of the supplementation was to provide an additional $100 \mathrm{Kcal}$ with 8-10 g protein per day. Participants or their care-providers were called on weekly basis to provide nutritional supplementation powder. This gave the research team an indication of participant compliance towards nutrient supplementation, as well as any issues or complications that emerged. Participants were also instructed to return with the empty container after completion of the intervention.

\section{Statistical analysis}

Qualitative variables of participant characteristics were reported as numbers or percentages, whilst quantitative data were reported as the mean \pm standard deviation (SD). Normality assumption among the groups was tested using the Kolmogorov-Smirnov Test. If normality was established, one-way ANOVA was carried out to see the association among the groups for quantitative variables and Chi-Square/Fischer Exact Test for qualitative variables. Paired t-tests were used to find the pre and post intervention differences within the group for quantitative data and McNemar's Chi-Square Test for qualitative data. Kruskal Wallis Test was used to find the actual change effect among the groups. A $p$-value $<0.05$ was considered as statistically significant.

\section{Results}

The ages of participants (mean \pm SD) in groups A, B, C were $75.77 \pm 6.25,76.88 \pm 5.89$ and $77.41 \pm 3.78$ years, respectively $(p=0.607)$. Table. 1 shows both quantitative and qualitative data at baseline. Similar baseline demographics were noted in each group and there were no statistically significant differences in age, gait speed, grip strength, BADL, IADL, serum albumin concentration and qualitative parameters such as GDS, HMSE, MNA, MPPT, BBS and frailty score.

Participants' gait speed (mean \pm SD) in groups A, B and $C$ were $0.66 \pm 0.11,0.67 \pm 0.10$ and $0.67 \pm 0.11$ respectively. There was significant effect of intervention on gait speed in group $\mathrm{A}(p=0.001)$ and $\mathrm{C}(p=0.002)$, but not in group $\mathrm{B}(p=0.926)$. Grip strength (mean $\pm \mathrm{SD})$ in groups $\mathrm{A}, \mathrm{B}$ and $\mathrm{C}$ were $8.91 \pm 2.11 \mathrm{~kg}, 9.09 \pm 2.20 \mathrm{~kg}$ and $8.45 \pm$ $2.32 \mathrm{~kg}$, respectively. No significant change was seen in grip strength in group $\mathrm{A}(p=0.488)$ and $\mathrm{B}(p=0.852)$, but a statistically significant increase was observed in group $C$ $(p=0.013)$. Intervention resulted in statistically significant increase in BADL and IADL scores for all three groups. While a significant effect on MPPT score was observed only in group $C(p=0.020)$, whilst a significant effect of intervention on the balance measure, BBS, occurred in group A $(p=0.046)$ and C $(p=0.024)$, but not in group B $(p=0.270)$ (Table 2).

There was statistically significant decrease in the serum albumin concentration in group A $(p<0.001)$, whilst groups $\mathrm{B}(p<0.001)$ and $\mathrm{C}$ group $(p<0.001)$ showed significant increases. A statistically significant $(p<0.001) \mathrm{im}$ provement in the nutritional status, as assessed by MNA, was also evident.

The effect of interventions on depression, as indicated by GDS score, showed significant improvement in groups B $(p=0.025)$ and $\mathrm{C}(p=0.021)$. There was no significant impact on cognition across interventions.

Among the study groups, a significant difference was observed in gait speed between groups $\mathrm{A}$ and $\mathrm{B}(p=$ $0.003), \mathrm{B}$ and $\mathrm{C}(p=0.012)$ but the difference was not significant between A and C $(p=0.944)$. The difference in albumin concentration was significant among groups $\mathrm{A}$ and B $(p<0.001)$ and groups A and C $(p<0.001)$, but not significant among groups $\mathrm{B}$ and $\mathrm{C}(p=0.603)$. A significant difference in BADL score was observed between group A and $C(p<0.001)$, and groups B and $C(p<0.001)$, but not between groups $\mathrm{A}$ and $\mathrm{B}(p=0.677)$ (Table 3$)$.

As shown in the Fig. 3, two participants $(9.09 \%)$ in group A became non-frail, one became frail (4.55\%) and the rest $(86.36 \%)$ remained as prefrail. For group B these figure were $4(18.18 \%), 2(9.09 \%)$ and $16(72.73 \%)$. In 
Table 1 Baseline characteristics of the study participants

\begin{tabular}{|c|c|c|c|c|}
\hline Variables & $\begin{array}{l}\text { Group A } \\
(n=22)\end{array}$ & $\begin{array}{l}\text { Group B } \\
(n=22)\end{array}$ & $\begin{array}{l}\text { Group C } \\
(n=22) \\
\end{array}$ & $p$-value \\
\hline \multicolumn{5}{|l|}{ Sex } \\
\hline Male & 13 & 11 & 18 & 0.078 \\
\hline Female & 9 & 11 & 4 & \\
\hline Age $\pm S D$ (years) & $75.7 \pm 6.24$ & $76.68 \pm 5.8$ & $77.4 \pm 3.78$ & 0.607 \\
\hline $\begin{array}{l}\text { Gait speed } \pm \text { SD } \\
\text { (metre/sec) }\end{array}$ & $0.66 \pm 0.1$ & $0.67 \pm 0.1$ & $0.67 \pm 0.1$ & 0.970 \\
\hline $\begin{array}{l}\text { Grip strength } \\
\pm \mathrm{SD}(\mathrm{Kg})\end{array}$ & $8.90 \pm 2.1$ & $9.09 \pm 2.2$ & $8.45 \pm 2.32$ & 0.620 \\
\hline BADL & $3.95 \pm 1.46$ & $3.36 \pm 0.90$ & $3.77 \pm 1.15$ & 0.251 \\
\hline IADL & $1.40 \pm 0.50$ & $1.36 \pm 0.58$ & $1.59 \pm 1.00$ & 0.555 \\
\hline $\begin{array}{l}\text { Serum albumin } \\
(\mathrm{g} / \mathrm{dl})\end{array}$ & $4.24 \pm 0.48$ & $3.97 \pm 0.47$ & $4.07 \pm 0.55$ & 0.207 \\
\hline \multicolumn{5}{|l|}{ GDS } \\
\hline$<5$ & 10 & 11 & 6 & 0.268 \\
\hline$\geq 5$ & 12 & 11 & 16 & \\
\hline \multicolumn{5}{|l|}{ HMSE } \\
\hline$<24$ & 10 & 9 & 9 & 0.940 \\
\hline$\geq 24$ & 12 & 13 & 13 & \\
\hline \multicolumn{5}{|l|}{ MNA } \\
\hline Malnourished & 9 & 9 & 12 & 0.518 \\
\hline At the risk & 9 & 12 & 8 & \\
\hline Normal & 4 & 1 & 2 & \\
\hline \multicolumn{5}{|l|}{ MPPT } \\
\hline Severe & 11 & 11 & 13 & 0.538 \\
\hline Moderate & 6 & 9 & 7 & \\
\hline Mild & 3 & 0 & 0 & \\
\hline Non-frail & 2 & 2 & 2 & \\
\hline \multicolumn{5}{|l|}{ BBS } \\
\hline Low - risk & 5 & 5 & 5 & 1.000 \\
\hline Medium- risk & 15 & 16 & 15 & \\
\hline High - risk & 2 & 1 & 2 & \\
\hline Pre- frail status & 22 & 22 & 22 & 0.676 \\
\hline
\end{tabular}

Analysed by One-way ANOVA and Chi-square test

group C, 6 (27.27\%) became non-frail whilst 16 (72.73\%) remained pre-frail.

\section{Compliance with the protocol and adverse events}

All of the randomized participants completed the trial. The values for median compliance within all three groups were also $100 \%$. Diarrhea occurred in three participants receiving the nutritional supplement but they stopped the supplement for a week, and then restarted. No cardiovascular complications occurred during any testing or training sessions.

\section{Discussion}

NW is a promising and practicable intervention for the maintenance of functionality in late life. In the present study, gait speed significantly improved with NW alone and in combination with INS. However, lone nutritional supplementation without NW did not show any impact on the gait speed of pre-frail adults. Our finding support previous report by Figueiredo et al., who observed an improvement in gait speed in older individuals following NW practice, versus an over-ground walking comparison group [20]. The combination of NW and INS also improved grip strength, although this effect was not evident for either alone. An earlier study reported a significant change in the grip strength of elderly women who practiced NW for the same duration as the present study [41]. This difference across studies may arise from variations in the levels of baseline malnutrition, $45.45 \%$ being malnourished and $43.94 \%$ at risk of malnourishment in the current study. Further, it might require a longer duration for lone nutritional supplementation to show any impact on muscle strength under variations in levels of malnourishment. The combined intervention seems to have an additive or synergistic effect in improving the strength of hand muscles.

All three groups showed improvements in functionality, indicating the utility of diet and NW on this parameter. Such data also highlights the importance of readily-modifiable nutritional deficiency in functional decline. Improvement of functional status is a primary goal for vulnerable older adults [42]. A study conducted by Persson et al. on the effects of combined nutritional treatments, in patients at risk of protein-energy malnutrition, also showed improved functionality as compared to controls [43].

NW + INS and INS alone significantly improved participants' mood. Many forms of exercise can improve mood, with some of the efficacy of exercise mediated via a lowering of the immune-inflammatory cascade that is evident in depression, as well as in pre-frail and frail older adults [44]. Previous work indicates the positive effect of NW on mood [44, 45]. However, the present study showed no mood improvement in the NW alone group. This again may arise from variations in study populations, with diet being more relevant to mood improvement in the current study. Previous studies have indicated that diet could regulate mood due to increased availability of key compounds, such as tryptophan, which is a necessary precursor or serotonin synthesis, thereby linking to the long-standing effects of serotonin in mood regulation [46]. In addition, small sample size and unmeasured factors/confounders may have contributed to the differences across studies. It is also of note, that due to the bidirectional association between depression and frailty [47], mood improvement may have a direct 
Table 2 Effect of intervention on different variables within groups

\begin{tabular}{|c|c|c|c|c|c|c|c|c|c|c|}
\hline \multirow[t]{2}{*}{ Variables } & \multirow[t]{2}{*}{ Categories } & \multicolumn{3}{|l|}{ Group A } & \multicolumn{3}{|l|}{ Group B } & \multicolumn{3}{|l|}{ Group C } \\
\hline & & Pre & Post & $p$-value & Pre & Post & $p$-value & Pre & Post & $p$-value \\
\hline Gait Speed & & $0.66 \pm 0.11$ & $0.99 \pm 0.41$ & 0.001 & $0.67 \pm 0.11$ & $0.66 \pm 0.10$ & 0.926 & $0.67 \pm 0.10$ & $1.00 \pm 0.45$ & 0.002 \\
\hline Grip Strength & & $8.9 \pm 2.1$ & $8.27 \pm 3.9$ & 0.488 & $9.09 \pm 2.2$ & $9.22 \pm 2.5$ & 0.852 & $8.45 \pm 2.3$ & $9.86 \pm 2.8$ & 0.013 \\
\hline BADL & & $3.95 \pm 1.46$ & $5.27 \pm 1.20$ & $<0.001$ & $3.36 \pm 0.90$ & $4.81 \pm 0.90$ & $<0.001$ & $3.77 \pm 1.15$ & $6.40 \pm 0.95$ & $<0.001$ \\
\hline IADL & & $1.40 \pm 0.50$ & $2.59 \pm 1.00$ & $<0.001$ & $1.36 \pm 0.58$ & $2.22 \pm 0.81$ & $<0.001$ & $1.59 \pm 1.00$ & $3.31 \pm 1.21$ & $<0.001$ \\
\hline Serum Albumin & & $4.24 \pm 0.48$ & $3.93 \pm 0.48$ & $<0.001$ & $3.97 \pm 0.47$ & $4.26 \pm 0.5$ & $<0.001$ & $4.07 \pm 0.5$ & $4.40 \pm 0.49$ & $<0.001$ \\
\hline \multirow[t]{3}{*}{ MNA } & Malnourished & 9 & 12 & 0.050 & 9 & 1 & 0.005 & 12 & 0 & 0.003 \\
\hline & At the risk & 9 & 9 & & 12 & 20 & & 8 & 17 & \\
\hline & Normal & 4 & 1 & & 1 & 1 & & 2 & 5 & \\
\hline \multirow[t]{4}{*}{ MPPT } & Severe & 11 & 6 & & 11 & 8 & & 13 & 2 & \\
\hline & Moderate & 6 & 11 & 0.226 & 9 & 12 & 0.072 & 7 & 4 & 0.020 \\
\hline & Mild & 3 & 4 & & 0 & 2 & & 0 & 12 & \\
\hline & Non-frail & 2 & 1 & & 2 & 0 & & 2 & 4 & \\
\hline \multirow[t]{3}{*}{ BBS } & Low-risk & 5 & 3 & & 5 & 4 & & 5 & 3 & \\
\hline & Medium-risk & 15 & 10 & 0.046 & 16 & 14 & 0.270 & 15 & 10 & 0.024 \\
\hline & High-risk & 2 & 9 & & 1 & 4 & & 2 & 9 & \\
\hline \multirow[t]{3}{*}{ Frailty } & Non-frail & 0 & 2 & & 0 & 4 & & 0 & 6 & \\
\hline & Pre-frail & 22 & 19 & 0.035 & 22 & 16 & 0.01 & 22 & 16 & 0.001 \\
\hline & Frail & 0 & 1 & & 0 & 2 & & 0 & 0 & \\
\hline \multirow[t]{2}{*}{ GDS } & $<5$ & 10 & 9 & 0.739 & 11 & 16 & 0.025 & 6 & 14 & 0.021 \\
\hline & $\geq 5$ & 12 & 13 & & 11 & 6 & & 16 & 8 & \\
\hline \multirow[t]{2}{*}{ HMSE } & $<24$ & 12 & 13 & 0.564 & 13 & 12 & 0.564 & 13 & 10 & 0.083 \\
\hline & $\geq 24$ & 10 & 9 & & 9 & 10 & & 9 & 12 & \\
\hline
\end{tabular}

Paired t-test and Mc Nemar's Chi-Square test was performed to see the effect within the groups

impact on the functionality of an individual and vice versa, possibly via immune-inflammatory regulation, including as arising from alterations in the microbiome and associated intestinal permeability. Many dietary factors can also act to regulate cognition, including more directly via brain neurotransmitter pathways, synaptic transmission, membrane fluidity and signal-transduction pathways [48], whilst diet and exercise may interact at the molecular level to influence cognitive abilities [48]. However, neither solitary nor multimodal interventions in the present study had any impact on cognitive status. This may have arisen due to the relatively short duration of the current pilot study, given that increased physical activity for at least 6 months may be necessary to improve cognition in older adults [49]. The current results also highlight the role of these simple interventions in the improvement of overall physical performance, as indicated by better frailty score in $18.18 \%$ of total study participants. However, intervention for a short duration might not show any significant impact on parameters

Table 3 Intervention effects across groups

\begin{tabular}{|c|c|c|c|c|c|c|c|}
\hline \multirow[t]{2}{*}{ Variables } & \multirow{2}{*}{$\begin{array}{l}\text { Group A } \\
\text { Median (Min, Max) }\end{array}$} & \multirow[t]{2}{*}{ GROUP B } & \multirow[t]{2}{*}{ GROUP C } & \multicolumn{4}{|l|}{$p$-value } \\
\hline & & & & $A$ Vs B Vs C & $A \vee s B$ & A Vs C & $\mathrm{B}$ Vs C \\
\hline Grip strength (Kg) & $-1.5(-6,7)$ & $0.5(-8,5)$ & $1(-2,7)$ & 0.10 & - & - & - \\
\hline BADL & $1.5(0,2)$ & $1.5(0,3)$ & $3(1,3)$ & 0.001 & 0.677 & $<0.001$ & $<0.001$ \\
\hline Serum albumin (g/dl) & $-0.3(-1.1,0.09)$ & $0.25(0,0.7)$ & $0.3(-0.29,0.8)$ & $<0.001$ & $<0.001$ & $<0.001$ & 0.603 \\
\hline Gait speed (m/s) & $0.33(-0.33,1.71)$ & $0(-0.2,0.4)$ & $0.21(-0.3,1.2)$ & 0.007 & 0.003 & 0.944 & 0.012 \\
\hline IADL & $0(0,2)$ & $1(0,2)$ & $3.72(0,4)$ & 0.013 & 0.258 & 0.055 & 0.005 \\
\hline
\end{tabular}

$p<0.016$ was considered to be significant for multiple comparison (Kruskal-Wallis test followed by Wilcoxon Rankson test) 


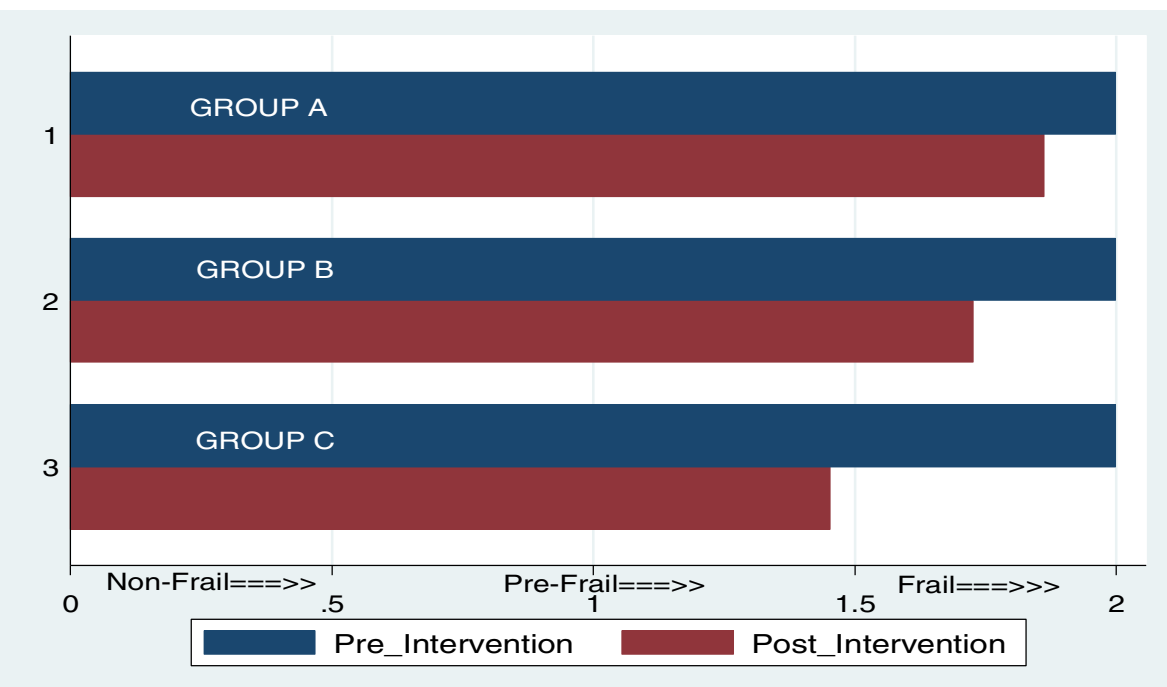

Fig. 3 Frailty status on Pre and Post intervention

such as weight loss, self reported physical exertions and physical performance (Fig. 4).

A recently published review of 17 studies of older adults ( $>65$ years) showed enhanced benefits of exercise training when combined with dietary supplementation [50]. This review also included studies of nutrition and exercise interventions aiming to impact on mass and/or muscle strength as indicants of improved physical performance [50].A study conducted by Rydwik et al. similarly showed a positive effect on lower-extremity muscle strength after a multi modal intervention [51]. The data of the present and previous studies are promising and of significant clinical importance, including as indicated by the comfort and high compliance with which older Indians practiced NW, coupled to no adverse events. Importantly, NW is regarded as a safe form of physical activity that helps in maintaining the body's centre of gravity, thereby decreasing the risk of falls [52]. Further, NW can be performed by individuals who have relatively low levels of endurance and requires no added supervision. It is clear that this pilot study requires replication in a larger cohort and for a longer duration.

This is the first study to have focused on a simple, yet effective intervention model in pre-frail older adults from India. With proper health awareness among various society stakeholders, NW and INS can be incorporated as a healthy life style, thereby promoting active and healthy aging in late life.

\section{Limitation of the study}

A major limitation of this study was that there was no non-treatment or control group. Further, this is a pilot study that clearly requires investigation in a larger cohort for a longer duration. Given the small sample size and the diversity of geriatric populations, the findings cannot be generalized.

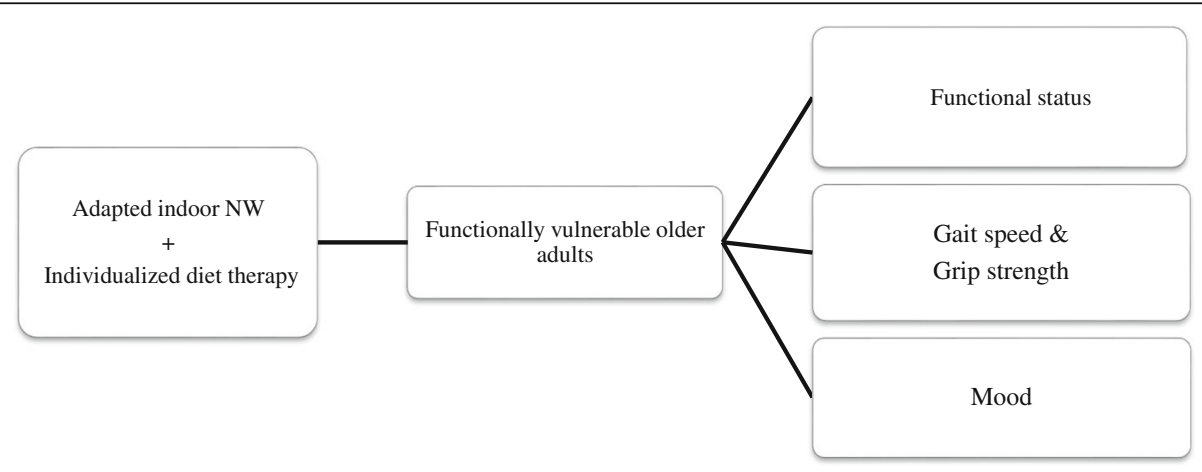

Fig. 4 Changes in various domains after multimodal intervention 


\section{Conclusions}

NW and INS were a simple pragmatic interventions to better optimize the benefits of exercise and nutrition on the functionally of vulnerable, pre-frail, older adults, allowing their greater independence. Although indications of some benefits are shown from NW and INS alone, there combination seems more effective in preventing the shift from a pre-frail to frail state. The current data need to be replicated and extended in a larger cohort with a longer follow-up period.

\section{Abbreviations \\ AllMS: All India Institute of Medical Sciences; BADL: Barthel activity of daily living; BBS: Berg balance scale; BMI: Body mass index; GDS: Geriatric depression scale; HMSE: Hindi mental status examination; IADL: Instrumental activity of daily living; IEC: Institutional ethical committee; INS: Individualized nutritional supplementation; INWA: International Nordic walking federation; MNA: Mini nutritional assessment; MPPT: Modified physical performance test; MUAC: Mid upper arm circumference; NW: Nordic walking; SD: Standard deviation}

\section{Acknowledgements}

The research group acknowledges, with thanks, the supports rendered by all faculties and staff of the Department of Geriatric Medicine and most importantly the study participants and care provider who proactively brought their seniors to the hospital for the intervention. The study was financially supported by the funds from National Programme for Health Care of the Elderly (NPHCE), Government of India.

\section{Funding}

National Programme for Health Care of the Elderly (NPHCE) was launched by Ministry of Health and Family Welfare, Government of India to fund Regional Geriatric Centres to carry out research. Department of Geriatric Medicine, AllMS, New Delhi is one such centre recognized by the Government of India. The funding body did not have any role in the design of the study nor in the collection, analysis, interpretation of the data and in the writing the manuscript.

\section{Availability of data and materials}

Data and material are available from the principal investigator, who is also the corresponding author of this manuscript.

\section{Authors' contributions}

First author PC1 conceived and designed the entire study and was also involved in the conceptualization and preparation of the first draft of the manuscript. PK conceived, designed, initiated the concept of Nordic walking and reviewed and modified the manuscript. RK, RM and MT were involved in data collection. DAK assisted the first author in writing the manuscript. GD and PC2 were involved in the revision of the manuscript. MAK, KG and SG performed the statistical analysis and wrote the results. Corresponding author ABD was involved in conceptualization of the concept along with the first author and guided in writing the entire manuscript. All authors read and approved the final version of the manuscript.

\section{Competing interest}

The authors declare that they have no competing interests.

\section{Ethics approval and consent to participate}

Ethical approval was obtained from the All India Institute of Medical Sciences Institute Ethics Committee and was in compliance with the 1964 Helsinki Declaration and its later amendments or comparable ethical standards. Participants fulfilling the inclusion criteria were recruited into the study after obtaining their informed written consent.

\section{Consent for publication}

Explicit written consent was obtained from the participant included in Fig. 1 for publication.

\section{Publisher's Note}

Springer Nature remains neutral with regard to jurisdictional claims in published maps and institutional affiliations.

\section{Author details}

${ }^{1}$ Department of Geriatric Medicine, All India Institute of Medical Sciences, New Delhi, India. ${ }^{2}$ Division of Geriatric Medicine, Patan Academy of Health Sciences, Patan, Nepal. ${ }^{3}$ Healthy Aging India, New Delhi, India. ${ }^{4}$ Department of Biostatistics, All India Institute of Medical Sciences, New Delhi, India.

${ }^{5}$ Corner Office Advisors, New Delhi, India. ${ }^{6}$ University of Manitoba, Winnipeg, Canada.

Received: 7 April 2018 Accepted: 23 August 2018

Published online: 14 September 2018

References

1. Frailty is the most problematic expression of population ageing". British Geriatrics Society. 2018. Available at: https://britishgeriatricssociety. wordpress.com/2017/04/21/frailty-is-the-most-problematic-expression-ofpopulation-ageing/. Accessed 5 April 2018.

2. Clegg A, Young J, lliffe S, Rikkert M, Rockwood K. Frailty in elderly people. Lancet. 2013;381(9868):752-62. https://doi.org/10.1016/s0140-6736(12)62167-9.

3. Halter J B, Ouslander JG, Studenski S, High K P, Asthana S, Supiano M A, Ritchie C. Hazzard's Geriatric Medicine and Gerontology. Seventh edition. New York, N.Y. : McGraw-Hill Education LLC., 2017.

4. Romero-Ortuno R, O'Shea D. Fitness and frailty: opposite ends of a challenging continuum! Will the end of age discrimination make frailty assessments an imperative? Age Ageing. 2013;42(3):279-80. https://doi.org/ 10.1093/ageing/afs189.

5. Sergi G, Veronese N, Fontana L, De Rui M, Bolzetta F, Zambon S. Pre-frailty and risk of cardio vascular disease in elderly men and women. J Am Coll Cardiol. 2015;65(10):976-83. https://doi.org/10.1016/j.jacc.2014.12.040.

6. Bagshaw SM, Stelfox HT, McDermid RC, et al. Association between frailty and short- and long-term outcomes among critically ill patients: a multicentre prospective cohort study. CMAJ : Canadian Medical Association Journal. 2014;186(2):E95-E102. https://doi.org/10.1503/cmaj.130639.

7. Collard RM, Boter $\mathrm{H}$, Schoevers RA, et al. Prevalence of frailty in communitydwelling older persons: a systematic review. J Am Geriatr Soc. 2012;60(8): 1487-92. https://doi.org/10.1111/j.1532-5415.2012.04054.x.

8. Chatterjee P, Krishnaswamy B. Prevalence and predisposing factors of frailty syndrome in elderly (> 75 YEARS) Indian population in subacute care setup. J Aging Res Clin practice. 2012;1(1):3-5.

9. Fairhall N, Kurrle SE, Sherrington C, Lord SR, Lockwood K, John B, et al. Effectiveness of a multifactorial intervention on preventing development of frailty in pre-frail older people: study protocol for a randomized controlled trial BMJ Open. 2015;5:e007091. https://doi.org/10.1136/bmjopen-2014-007091.

10. Cameron I D, Fairhall N, Gill L, et al. Developing Interventions for Frailty. Advances in Geriatrics 2015, Article ID 845356, 7 pages, 2015. doi:https://doi. org/10.1155/2015/845356.

11. Morley JE, Baumgartner RN, Roubenoff R, Mayer J, Nair KS. Sarcopenia. J Lab Clin Med. 2001;137(4):231-43. https://doi.org/10.1067/mlc.2001.113504.

12. Santilli V, Bernetti A, Mangone M, Paoloni M. Clinical definition of sarcopenia. Clinical Cases in Mineral and Bone Metabolism. 2014;11(3): 177-80.

13. Michel J-P, Cruz-Jentoft AJ, Cederholm T. Frailty, exercise and nutrition. Clin Geriatr Med. 2015;31:375-87. https://doi.org/10.1016/j.cger.2015.04.006.

14. Tomás MT, Galán-Mercant A, Carnero EA, Fernandes B. Functional capacity and levels of physical activity in aging: a 3-year follow-up. Front Med. 2018; 4:244. https://doi.org/10.3389/fmed.2017.00244.

15. Ossowski ZM, Skrobot W, Aschenbrenner P, Cesnaitiene VJ, Smaruj M. Effects of short-term Nordic walking training on sarcopenia-related parameters in women with low bone mass: a preliminary study. Clin Interv Aging. 2016;11:1763-71. https://doi.org/10.2147/CIA.S118995.

16. Tieland $M$, van de Rest $O$, Dirks ML, van der Zwaluw N, Mensink M, van Loon L, de Groot LC. Protein supplementation improves physical performance in frail elderly people: a randomized, double-blind, placebocontrolled trial. J Am Med Dir Assoc. 2012;13(8):720-6. https://doi.org/10. 1016/j.jamda.2012.07.005.

17. Morgulec-Adamowicz N, Marszałek J, Jagustyn P. Nordic walking-a new form of adapted physical activity (a literature review). Human Movement. 2011;12(2):124-32. https://doi.org/10.2478/v10038-011-0009-7. 
18. AAHF. Articles: aging. Aahfinfo: Exercise and Motivation; 2018. http://aahf.info/ sec_news/section/aging-motivation_petersen_012407.htm. Accessed 5 April 2018

19. Notthoff N, Carstensen LL. Positive messaging promotes walking in older adults. Psychol Aging. 2014;29(2):329-41. https://doi.org/10.1037/a0036748.

20. Figueiredo S, Finch L, Mai J, Ahmed S, Huang A, Mayo NE. Nordic walking for geriatric rehabilitation: a randomized pilot trial. Disabil Rehabil. 2013: 35(12):968-75. https://doi.org/10.3109/09638288.2012.717580.

21. Tschentscher $M$, Niederseer $D$, Niebauer J. Health benefits of Nordic walking. Am J Prev Med. 2013;44(1):76-84. https://doi.org/10.1016/j.amepre.2012.09.043.

22. Schiffer T, Knicker A, Hoffman U, Harwig B, Hollmann W, Strüder HK. Physiological responses to Nordic walking, walking and jogging. Eur J Appl Physiol. 2006;98:56-61. https://doi.org/10.1007/s00421-006-0242-5.

23. British Nordic Walking | Instructor Training | Nordic Walking Events. British Nordic Walking. 2018. Available at: https://britishnordicwalking.org.uk/. Accessed 5 April 2018.

24. Mors $\varnothing$ L, Hartvigsen J, Puggaard L, Manniche C. Nordic walking and chronic low back pain: design of a randomized clinical trial. BMC Musculoskelet Disord. 2006;7(77):21e26. https://doi.org/10.1186/1471-2474-7-77.

25. Bullo V, Gobbo S, Vendramin B, Cugusi L, Di BA, et al. Nordic walking can be incorporated in the exercise prescription to increase aerobic capacity, strength, and quality of life for elderly: a systematic review and metaanalysis. Rejuvenation Res. 2017; https://doi.org/10.1089/rej.2017.1921.

26. Fukagawa NK, Young VR. Protein and amino acid metabolism and requirements in older persons. Clin Geriatr Med. 1987;3(2):329-41.

27. Morais JA, Chevalier S, Gougeon R. Protein turnover and requirements in the healthy and frail elderly. J Nutr Health Aging. 2006;10(4):272-83.

28. Baum Jl, Kim I-Y, Wolfe RR. Protein consumption and the elderly: what is the optimal level of intake? Nutrients. 2016;8(6):359. https://doi.org/10.3390/ nu8060359.

29. Fujita S, Volpi E. Amino acids and muscle loss with aging. J Nutr. 2006;136(1 Suppl):277S-80S

30. Fried LP, Tangen CM, Walston J. Frailty in older adults: evidence for a phenotype. J Gerontol A BiolSci Med Sci. 2001;56(3):M146-56.

31. Guigoz Y, Vellas B, Garry PJ. Mini Nutritional Assessment: a practical assessment tool for grading the nutritional state of elderly patients. Facts Res Gerontol. 1994;4(suppl 2):15.

32. Reuben DB, Siu AL. An objective measure of physical function of elderly outpatients. The physical performance test. J Am Geriatr Soc. 1990;38(10): 1105-12. https://doi.org/10.1111/j.1532-5415.1990.tb01373.x

33. Berg K, Wood-Dauphinee S, Williams J, et al. Measuring balance in the elderly: preliminary development of an instrument. Physiother Can. 1989; 41(6):304-11. https://doi.org/10.3138/ptc.41.6.304

34. Wade DT, Collin C. The Barthel ADL index: a standard measure of physical disability? Int Disabil Stud. 1988;10(2):64-7.

35. Lawton M.P, Brody E.M. Assessment of older people: self-maintaining and instrumental activities of daily living. Gerontologist 1969;9: 179-186.

36. Greenberg SA. How to try this: the geriatric depression scale: short form. Am J Nurs. 2007;107(10):60-9. https://doi.org/10.1097/01.NAJ.0000292204. 52313.f3.

37. Ganguli M, Ratcliff G, Chandra V, Sharma S, Gilby J, Pandav R, et al. A Hindi version of the MMSE: the development of a cognitive screening instrument for a largely illiterate rural elderly population in India. International Journal of Geriatric Psychiatry. 1995;10(5):367-77.

38. Gunasekaran V, Banerjee J, Dwivedi SN, Upadhyay AD, Chatterjee P, Dey AB. Normal gait speed, grip strength and thirty seconds chair stand test among older Indians. Arch Gerontol Geriatr. 2016;67:171-8.

39. Homepage - INWA. INWA. 2018. Available at: http://www.inwanordicwalking.com/. Accessed 5 April 2018.

40. Pai MK. Comparative study of nutritional status of elderly population living in the home for aged Vs those living in the community. Biomedical Research. 2011;22(1):120-6.

41. Song MS, Yoo YK, Choi CH, Kim NC. Effects of nordic walking on body composition, muscle strength, and lipid profile in elderly women. Asian Nurs Res (Korean Soc Nurs Sci). 2013;7(1):1-7. https://doi.org/10.1016/j.anr.2012.11.001.

42. Bierman AS. Functional status: the sixth vital sign. J Gen Intern Med. 2001; 16(11):785-6. https://doi.org/10.1111/j.1525-1497.2001.10918x.

43. Persson M, Hytter-Landahl Å, Brismar K, Cederholm T. Nutritional supplementation and dietary advice in geriatric patients at risk of malnutrition. Clin Nutr. 2007;26(2):216-24. https://doi.org/10.1016/j.clnu.2006.12.002.

44. Suija K, Pechter Ü, Kalda R, Tähepõld H, Maaroos J, Maaroos H. Physical activity of depressed patients and their motivation to exercise: Nordic walking in family practice. Int J Rehabil Res. 2009;32(2):132-8. https://doi. org/10.1097/mrr.0b013e32831e44ef.

45. Lee HS, Park JN. Effects of Nordic walking on physical functions and depression in frail people aged 70 years and above. J Phys Ther Sci. 2015; 27(8):2453-6. https://doi.org/10.1589/jpts.27.2453.

46. Rao TSS, Asha MR, Ramesh BN, Rao KSJ. Understanding nutrition, depression and mental illnesses. Indian J Psychiatry. 2008;50(2):77-82. https://doi.org/10. 4103/0019-5545.42391

47. Soysal P, Nicola V, Thompson T, Kahl KG, Fernandes BS, Prina AM. Solmi M et al. Relationship between depression and frailty in older adults: A systematic review and meta-analysis Ageing Research Reviews. 2017;36:7887. https://doi.org/10.1016/j.arr.2017.03.005.

48. Gómez-Pinilla F. Brain foods: the effects of nutrients on brain function. Nat Rev Neurosci. 2008;9(7):568-78. https://doi.org/10.1038/nrn2421.

49. Lautenschlager N, Cox K. Can participation in mental and physical activity protect cognition in old age? JAMA Intern Med. 2013;173(9):805. https://doi. org/10.1001/jamainternmed.2013.206.

50. Denison HJ, Cooper C, Sayer AA, Robinson SM. Prevention and optimal management of sarcopenia: a review of combined exercise and nutrition interventions to improve muscle outcomes in older people. Clin Interv Ageing. 2015;11(10):859-69. https://doi.org/10.2147/CIA.S55842.

51. Rydwik $E_{\text {, Lammes }}$, Frändin $\mathrm{K}$, Akner $\mathrm{G}$. Effects of a physical and nutritional intervention program for frail elderly people over age 75. A randomized controlled pilot treatment trial. Aging Clin Exp Res. 2008;20(2):159-70. https://doi.org/10.1007/bf03324763.

52. Dalton C. Effect of Nordic Walking on Older Adult Gait and Posture Available at https://ruor.uottawa.ca/bitstream/10393/34091/5/Dalton_ Christopher_2016_Thesis.pdf.Accessed June 3, 2018.

\section{Ready to submit your research? Choose BMC and benefit from:}

- fast, convenient online submission

- thorough peer review by experienced researchers in your field

- rapid publication on acceptance

- support for research data, including large and complex data types

- gold Open Access which fosters wider collaboration and increased citations

- maximum visibility for your research: over $100 \mathrm{M}$ website views per year

At $\mathrm{BMC}$, research is always in progress.

Learn more biomedcentral.com/submissions 